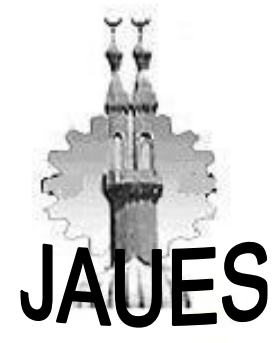

Journal of Al-Azhar University Engineering Sector

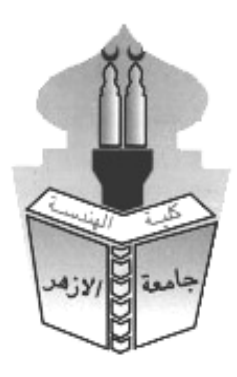

Vol,16. , No,61, October 2021,1212-1223

\title{
EFFECT OF MWCNTS ON MICROSTRUCTURE, DRY SLIDING WEAR, AND CORROSION BEHAVIOR OF AA5052/MWCNTS COMPOSITE
}

\author{
A. Magdy ${ }^{1}$, Amir A. Mahdy ${ }^{2}$, E.S. Mosa ${ }^{2}$, A. Kandil ${ }^{2}$ \\ ${ }^{1}$ Corrosion Engineer at Egyptian Maintenance Co. \\ ${ }^{2}$ Mining, Metallurgy and Petroleum Engineering Department, Al- Azhar University, Nasr City 11371, \\ Cairo, Egypt.
}

*Corresponding Author E-mail: amirmahdy.12@azhar.edu.eg

Received : 19 August 2021 Accepted: 8 September 2021

\begin{abstract}
Multi-walled carbon nanotubes (MWCNTs) reinforced aluminum AA5052 alloy was successfully fabricated using the stir casting method with the concentration of 0.05, 0.1, 0.2, and 0.3\% MWCNTs weight fractions. The effect of the MWCNTs addition on the composite microstructure was investigated using Light Optical Microscope (LOM) and Scanning Electron Microscope (SEM). Dry sliding wear and corrosion behavior of the synthesized composites have been analyzed. The results revealed that the increase of CNT content from zero to $0.3 \mathrm{wt}$. \% causes a reduction in the average grain size value up to 6 times finer than the base material grain size. The wear rate of AA5052MWCNTs composite materials improved, it decreases gradually from $8.3 \times 10^{-6} \mathrm{~g} / \mathrm{m}$ (base Matrix) to $7 \times 10^{-7} \mathrm{~g} / \mathrm{m}$ with increasing MWCNTs content up to $0.3 \mathrm{wt} . \%$. On the other hand, the corrosion resistance test of AA5052-MWCNTs composite materials was performed and showed that the corrosion rate of composites decreases from 14.72 to $3.27 \mu \mathrm{m} / \mathrm{Y}$ with increasing the MWCNTs content from 0.0 to $0.2 \mathrm{wt}$. $\%$.
\end{abstract}

KEYWORDS: MWCNTs, Stir casting, Grain refiner, Wear rate and Corrosion resistance.

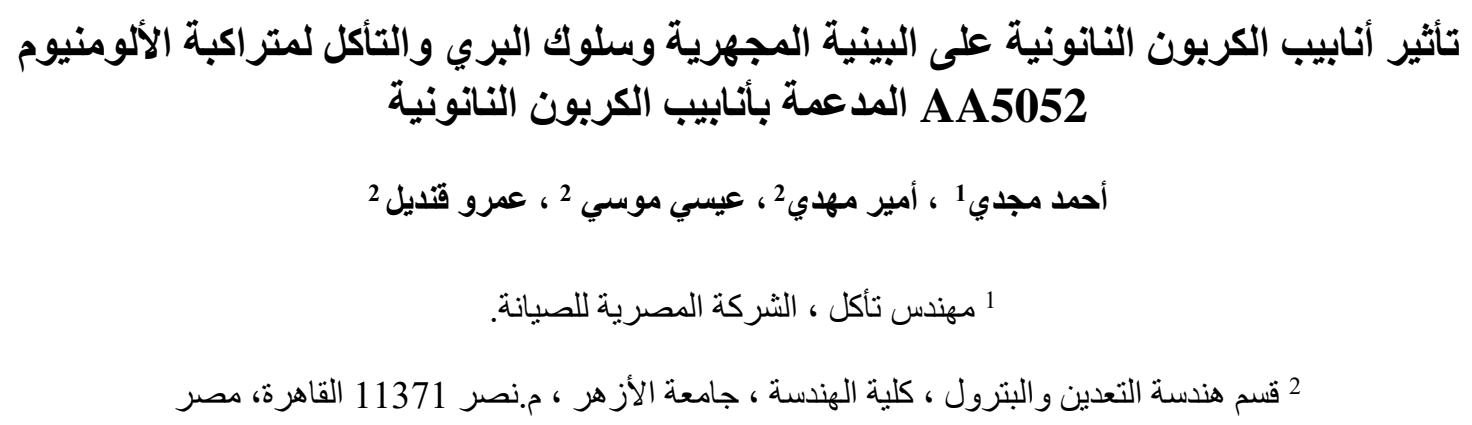




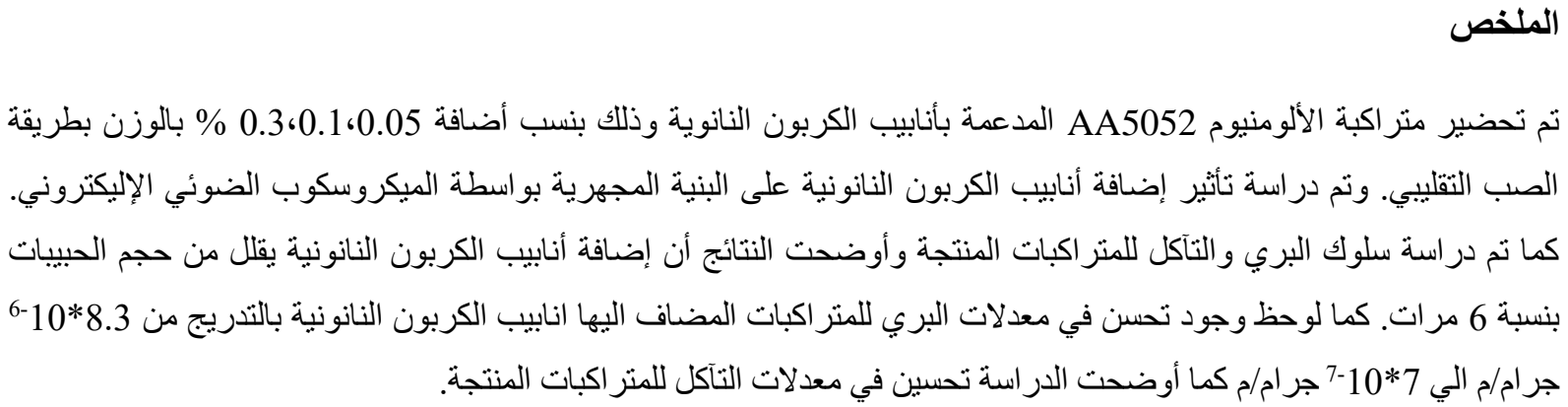

\section{INTRODUCTION}

In recent years, the pressing need to reduce fuel consumption and emissions in-ground and aerospace transportation have led to an increasing trend in employing light alloys to produce structural components. Furthermore, high-performance and low-weight structural materials are increasingly required in many industrial applications, including thermal management and automatic precision devices [1]. Aluminum and its alloys are considered major base materials for such purposes due to their lightweight and mechanical properties especially reinforced with suitable reinforcement materials.

Compared to its typical counterpart, iron, aluminum is a light metal with high corrosion resistance, high ductility, and low melting point that can be used in various industrial applications. Poor mechanical performance limits the proliferation of aluminum in other fields and applications [2].

Metal matrix composites (MMC) are an essential group of structural materials that can be used to fulfill some important requirements of the modern industry such as low density, high specific strength, high modulus, increased wear resistance, higher service temperature and in general, better mechanical performance compared with conventional monolithic materials. Al-based composites are an important area to study due to their attractive properties for diverse industrial and potential applications in the field of MMC [3].

Many literatures are concerned with the processing, microstructure, and properties of discontinuously reinforced metal matrix composites (MMCs). Reinforcements such as silicon carbide (SiC) [4-6], alumina $\left(\mathrm{Al}_{2} \mathrm{O}_{3}\right)$ [7-8], and boron carbide $\left(\mathrm{B}_{4} \mathrm{C}\right)$ [9] are regularly used in combination with a matrix needing an enhanced property or a set of properties.

Carbon nanotube (CNT) has been expected as an ideal reinforcement in composites due to its special structure, high strength, and stiffness, along with low density [10-13]. Due to some technical difficulties in experiments, continuum modeling has been extensively applied to the analyses of MWCNTS currently [14-16]. In addition, considerable work has been done to prepare CNT-reinforced metal matrix composites (MMCs) and characterize their elastic and plastic response [17].

There are many production processes used for the preparation of CNT-reinforced MMCs. Powder metallurgy [18-21], stir casting [22-25], ECAP [26-27], and FSP [28-30] are the most techniques used for such purpose.

In the present work, the effect of MWCNTs on the microstructure, dry sliding wear, and corrosion behavior of CNT reinforced AA5052 alloy has been investigated.

\section{EXPERIMENTAL PROCEDURES}

\subsection{Materials}

The composition of the aluminum matrix alloy (AA5052) used in the present work was listed in Table 1. This standard wrought alloy was received from Shandong Sino Aluminum Co., Ltd, China. Fabricated MWCNTs [25] with an inner diameter of $4.88 \mathrm{~nm}$ and $3.25 \mathrm{~nm}$ wall thickness with length 6-14 $\mathrm{mm}$ that used as a reinforcement in the present work. 
Table 1: Chemical composition of AA5052 alloy matrix

\begin{tabular}{|c|c|c|c|c|c|c|c|}
\hline Element & $\mathbf{M g}$ & $\mathbf{S i}$ & $\mathbf{C u}$ & $\mathbf{F e}$ & $\mathbf{Z n}$ & $\mathbf{C r}$ & $\mathbf{A l}$ \\
\hline Weight \% & 2.62 & 0.11 & 0.02 & 0.23 & 0.07 & 0.26 & Balance \\
\hline
\end{tabular}

\subsection{Casting Procedures}

Stir casting technique for producing (AA5052/MWCNTs) composite materials were applied. In the stir casting technique; $300 \mathrm{~g}$ of aluminum alloy (AA5052) was melted entirely at a temperature of $850^{\circ} \mathrm{C}$ in an electric heat resistance furnace, using a graphite crucible and three-blade graphite stirrer driven by a speed motor at 700-1100 r.p.m. as shown in Fig. 1 [25].

The melt temperature was measured using a $(\mathrm{Ni}-\mathrm{Cr} \mathrm{Ni})$ thermocouple when the melt temperature reached $700{ }^{\circ} \mathrm{C}$ above liquidus temperature; the melt was degassed with nitrogen for two minutes, then cleaning the surface of the melt from the oxide film by skimming. After complete skimming, we lowered the temperature gradually until the alloy reached a semisolid state. At this temperature (580 ${ }^{\circ} \mathrm{C}$ ), the reinforcing Al/MWCNTs capsules were introduced into the slurry, and a stirrer was inserted in the melt by stirring speed 700 r.p.m., the action of stirring combined with high viscosity of the slurry minimizing the tendency for settling, floating, or agglomeration of MWCNTs particles. For getting for a typical dispersion of MWCNTs particles, the melt was continuously stirred for 2 min and degassed after the addition of MWCNTs particles into the melt. The stirrer was then drawn and stopped, and the molten metal was poured at $700{ }^{\circ} \mathrm{C}$ into a preheated permanent steel mold $(30 \mathrm{~mm}$ diameter and 120 mm height).

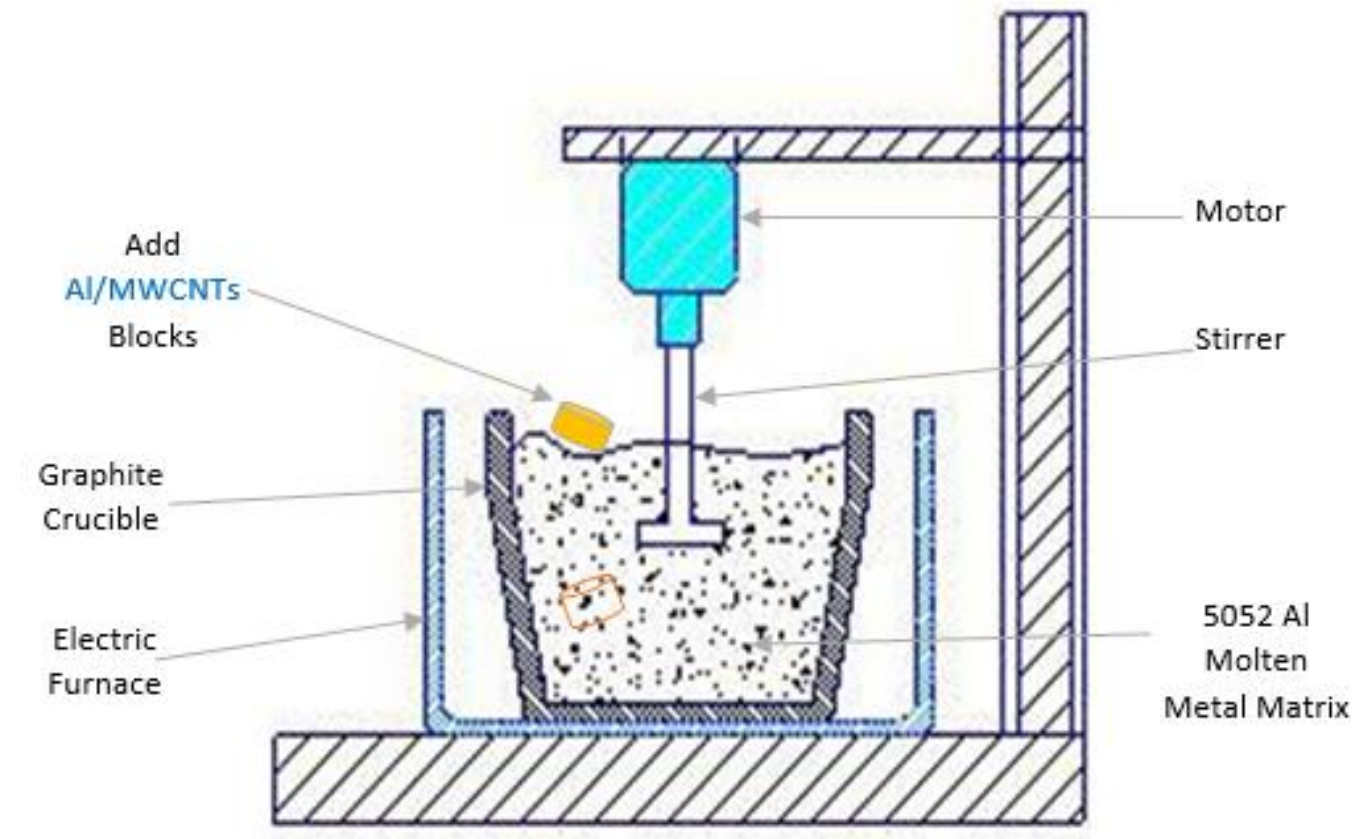

Fig. 1: The schematic diagram of the stir casting set-up used for the fabrication of the composite

(AA5052/MWCNTs) [25]

The composite samples were evaluated by using light microscopy (Leco LX 31-USA), equipped with a (PAX-Cam) digital camera and (PAXIT) software to examine the microstructure. The wear rate of the fabricated composites was measured using a pin-on-disc wear apparatus (DUCOM TR20-LE, at room temperature according to ASTMG99-04 standard, and the wear test was conducted at a constant sliding speed of $1.66 \mathrm{~m} / \mathrm{sec}$. The normal load of $5 \mathrm{~kg}$ and a total sliding distance of $3000 \mathrm{~m}$ with the 
corresponding test duration of $30 \mathrm{~min}$. Tafel polarization test was performed according to ASTM G5 and ASTM G52. The corrosion behavior of the composites produced was investigated in a distilled water solution with $3.5 \% \mathrm{NaCl}$ at room temperature by using a conventional three-electrode cell in Voltalab 40 PGZ 301-France. The cell is composed of a specimen as a working electrode, a saturated calomel electrode (SCE) as the reference electrode, and platinum as a counter electrode. Working electrodes were prepared by painting all surfaces, leaving $1.5 \mathrm{~cm}^{2}$ for exposure to the electrolyte. The conditions for the development of the Tafel polarization analysis were the following: initial electric potential $\left(\mathrm{E}_{\mathrm{i}}\right):-250 \mathrm{mV}$; final electric potential $\left(\mathrm{E}_{\mathrm{f}}\right): 250 \mathrm{mV}$; and a scan speed of $0.5(\mathrm{mV} / \mathrm{sec})$.

\section{RESULTS AND DISCUSSION}

\subsection{Microstructural Characterizations}
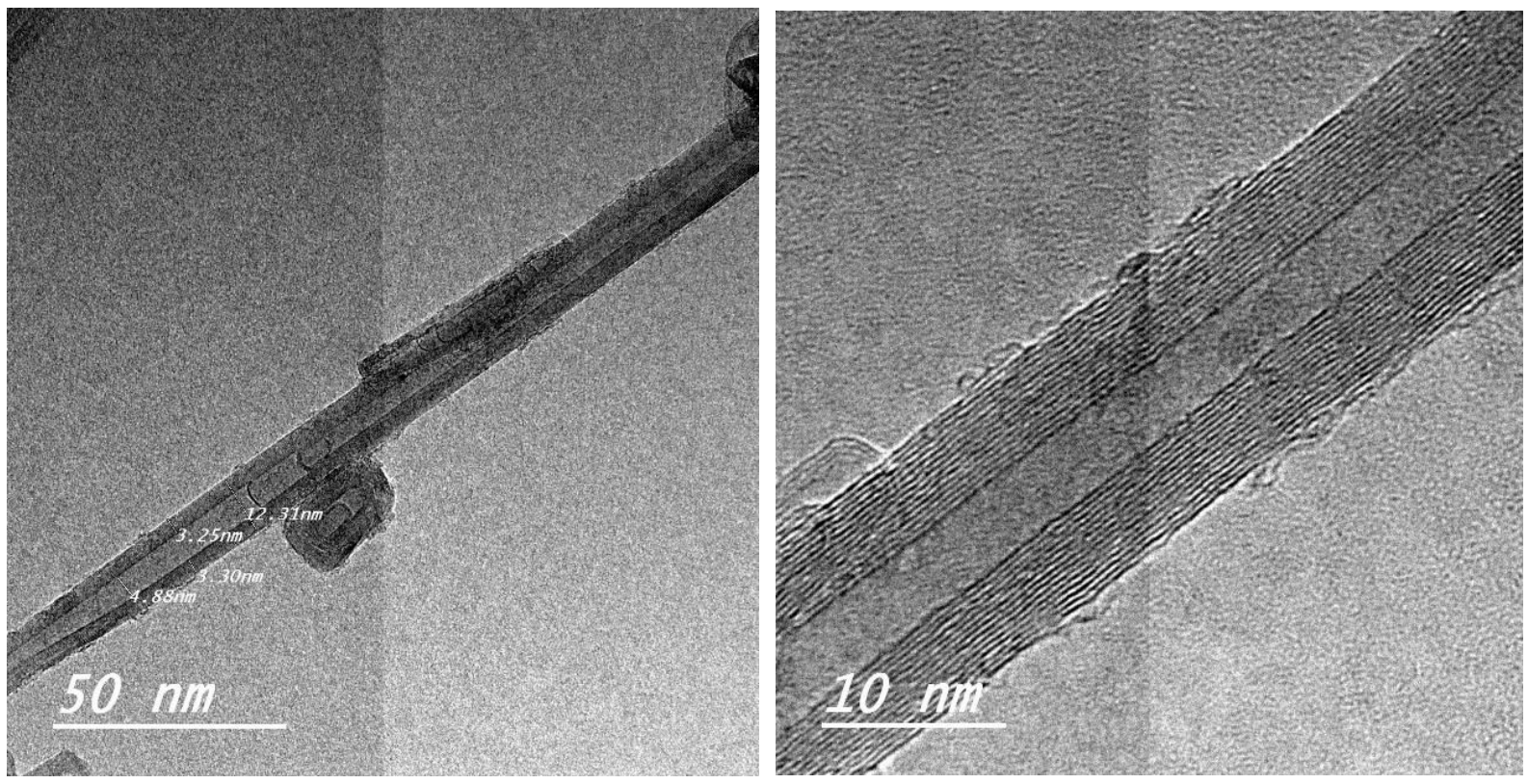

Fig.2: High-resolution transmission electron microscopy (HRTEM) image showing multi-walled carbon nanotubes (MWCNTs).

As shown in Fig. 2., fabricated MWCNTs produced using arc discharge technique [25] were measured $3.3 \mathrm{~nm}$ wall thickness, $4.88 \mathrm{~nm}$ inner diameter, and $12.31 \mathrm{~nm}$ outer diameter.

The initial structure of the investigated alloy, in accordance with the binary aluminum-magnesium system, consists of two phases. The main microstructure of the alloy's matrix consisting of $\alpha-\mathrm{Al}$ containing a small amount of solute $\mathrm{Mg}$ atoms, and the second phase $\beta-\mathrm{Al}_{3} \mathrm{Mg}_{2}$, as shown in Fig. 3. In aluminum alloy A5052, the precipitates of $\beta$ phase are mainly located on the grain boundaries. 

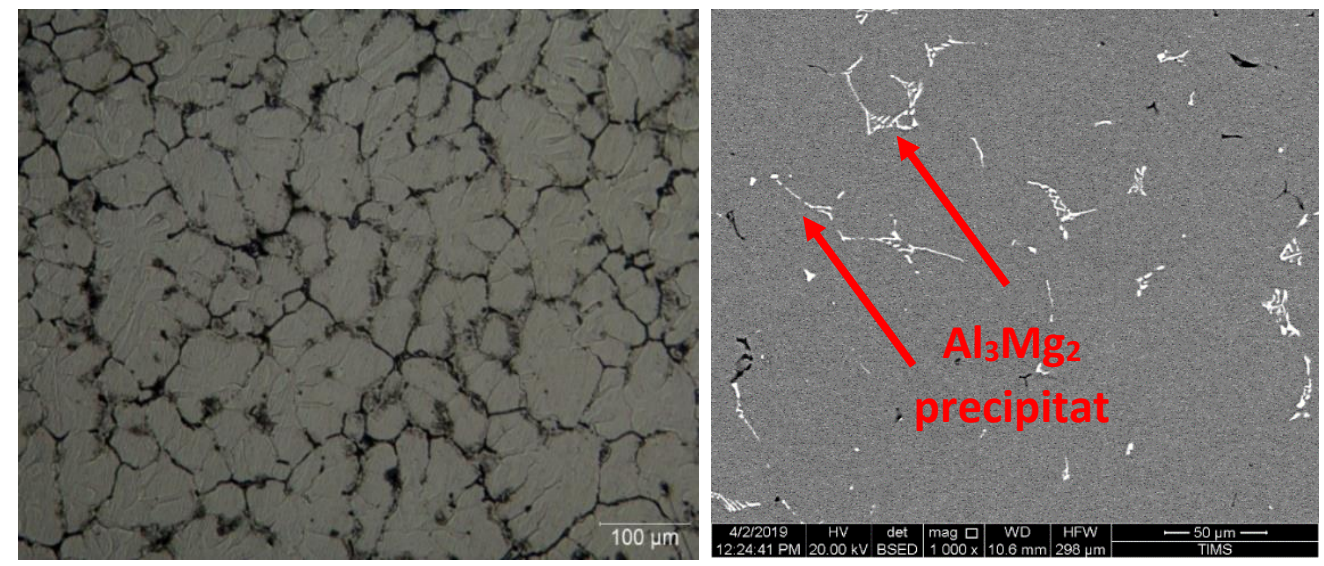

Fig.3: Optical Micrograph (a), and SEM image of the AA5052 (b)

\subsection{Effect Of Mwents On The Grain Size In AA 5052 Metal Matrix Nanocomposite}

One of the main strengthening mechanisms thought to be involved in the nanocomposite is grain refinement. Establishing the effect of CNT addition on grain size is necessary for understanding the behavior of aluminum alloy A5052. The influence of the addition of MWCNTs on the grain structure of aluminum alloy A5052 and the crystallographic orientation was investigated. Figure 4 shows the grain size maps produced with and without CNT.

The MWCNTs introduction promotes significant microstructural changes, either in grain size or in the formation of textures. The analysis of this figure showed that the addition of MWCNTs affects the crystallographic orientation of the grains. The micrographs show a layered structure with the color contrast representing different gradients of the morphological flow for the grain distortion between the layers; this aspect is essential since a strong texture can significantly affect the mechanical properties.
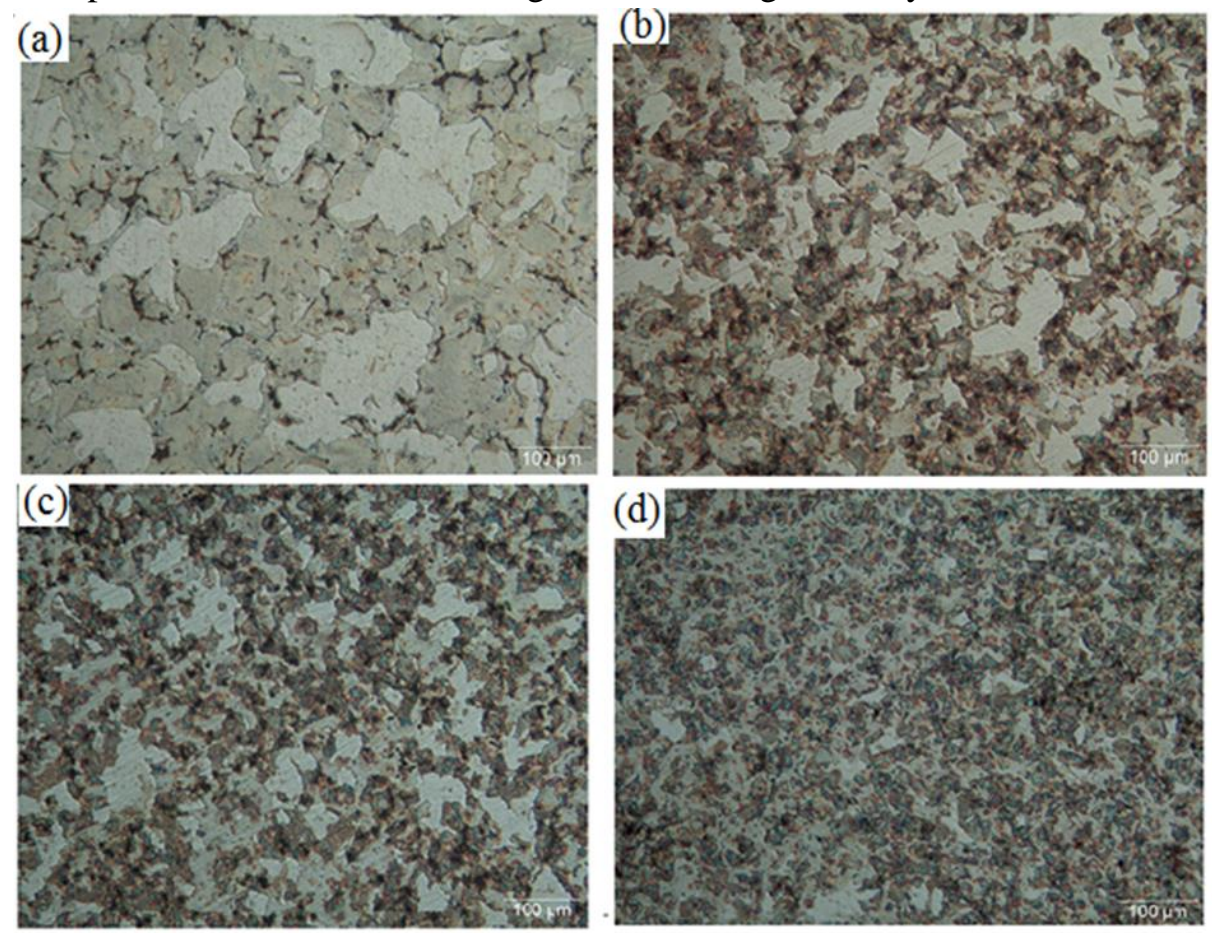

Fig. 4: Representative micrographs showing grain size in monolithic alloy AA 5052 and AA5052/CNT nanocomposite: (a) AA5052-0.0 wt. \% CNT (b) AA5052-0.1 wt. \%MWCNTs, (c) AA5052-0.2 wt. \%MWCNTs, and (d) AA5052- 0.3 wt. \% MWCNTs 


\section{EFFECT OF MWCNTS ON MICROSTRUCTURE, DRY SLIDING WEAR, AND CORROSION BEHAVIOR OF AA5052/MWCNTS COMPOSITE}

Formation of columnar grain structure is found in the matrix alloy (A5052), whereas a rosette-like irregular grain structure is observed in the developed composite, Fig 4-b. However, it is found that ultrafine grain microstructure is observed with a narrow range of distribution in the A5052/0.3wt.5\% CNT, Fig. 4-d.

In addition, the dispersed CNT acting as a grain refiner results in fine grains. Because of the high temperature, the difference between CNT and the molten metal, a high nucleation rate occurs in the melt. Those forms are rounded and Rosset-shaped grains. The grain refinement is clearly observed for A5052 /CNT nanocomposites. The results revealed that the increase of MWCNTs content from 0 to 0.3 wt. \% causes a reduction in the average grain size value up to 6 times finer than the base material grain size. The average grain size of monolithic alloy A5052 (0.0\% MWCNTs) and 0.3 wt. \% MWCNTs composite decreases from $180 \mu \mathrm{m}$ to $30 \mu \mathrm{m}$, respectively, Fig.5. This is because the introduction of MWCNTs provides more nucleation sites into the aluminum alloy A5052. In this study, carbon tubes with a size of $3.5 \mathrm{~nm}$ were used. Decreasing the MWCNTs reinforcement size results in more potent grain refinement and that although the initial decrease in grain size is considerable for small additions of reinforcement. The effect quickly levels off beyond $0.2 \mathrm{wt}$ \% addition.

The grain refinement effect has been attributed to the heterogeneous nucleation of the primary Al phase on MWCNTs and the restricted growth of Al crystals caused by the presence of rigid MWCNTs. Moreover, the presence of MWCNTs at the grain boundaries retarded the grain growth during the solidification process. Thus, grain refinement contributes to the great strength at room temperature for both $\mathrm{Al}$ alloys and the $\mathrm{Al}$ matrix composite. The influence of the grain size on the yield strength $[31,32]$ can be approximated using the standard Hall-Petch equation, which arose from experimental observations, of the form; $\sigma \mathrm{y} . \mathrm{s}=\sigma \mathrm{o}+\mathrm{kd}-0.5$

Where $\sigma$ is the yield stress, $\sigma_{0}$ is the yield stress of a single crystal, $\mathrm{K}$ a constant, and $\mathrm{d}$ is the grain size.

The value of K generally depends on the number of slip systems and is greater for HCP metals than for FCC and BCC metals.

Figure 5 shows the effect of MWCNTs addition on the average grain size of composite materials.

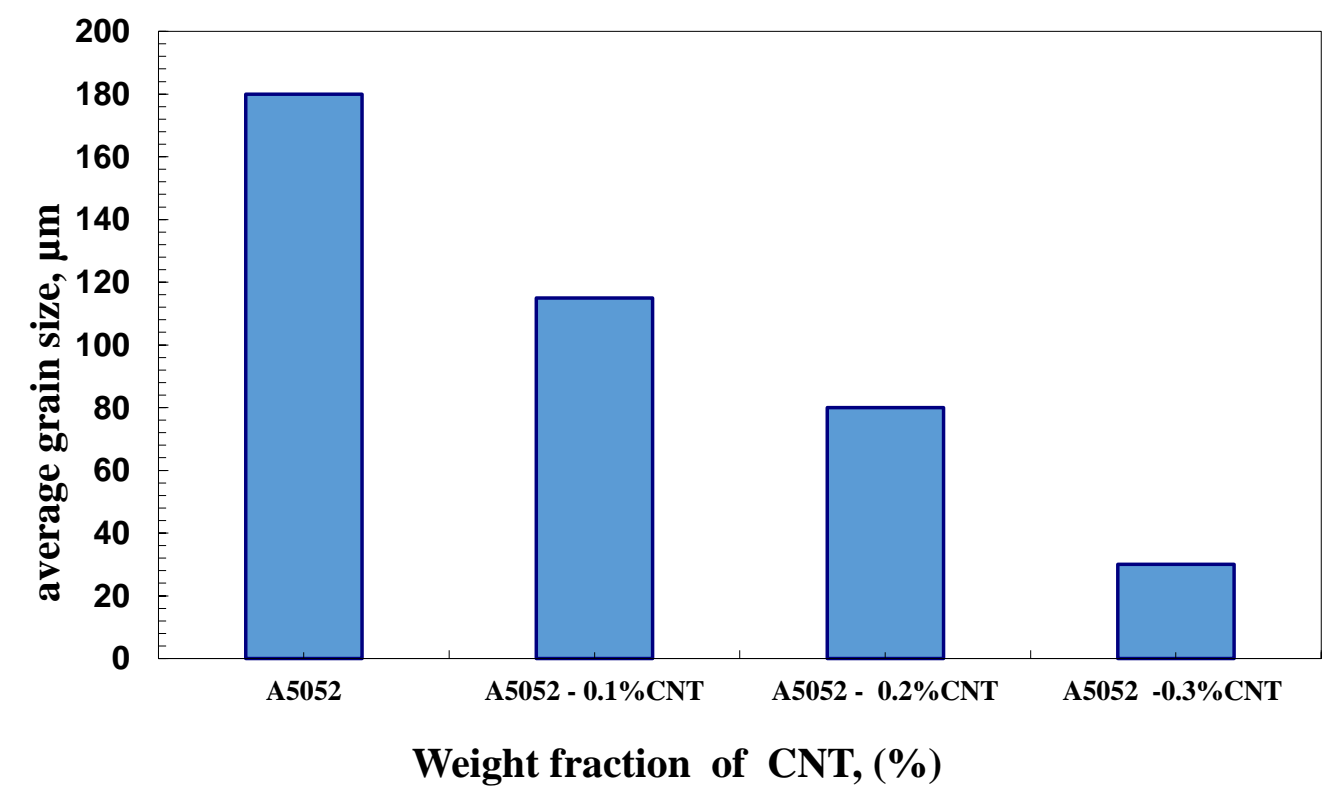

Fig.5: Effect of CNT addition on matrix grain size of aluminium alloy A5052 


\subsection{Wear Behavior}

The wear rates of AA5052/MWCNTs composite materials at a various weight percent of MWCNTs were calculated using equation (1) and is shown in Table 2

Wear rate $=($ weight loss $) /$ Sliding distance $(\mathrm{m})$

Table 2: Results of wear test for as-cast AA5052/MWCNTs \% composites as a function of MWCNTs content.

\begin{tabular}{cccc}
\hline Composite materials & $\begin{array}{c}\text { Original weight } \\
(\mathrm{gm})\end{array}$ & $\begin{array}{c}\text { Wear sample } \\
\text { weight }(\mathrm{gm})\end{array}$ & $\begin{array}{c}\text { Wear rate } \\
\mathrm{g} / \mathrm{m}\end{array}$ \\
\hline \hline AA5052 & 3.385 & 3.360 & 0.0000083 \\
AA5052/0.05 wt.\% & 3.550 & 3.535 & 0.0000050 \\
AA5052/0.1 wt.\% & 4.260 & 4.250 & 0.0000033 \\
AA5052/0.2 wt.\% & 3.590 & 3.585 & 0.0000017 \\
AA5052/0.3 wt. $\%$ & 3.600 & 3.598 & 0.0000007 \\
\hline \hline
\end{tabular}

Figure 6 presents the wear resistance behavior of as-cast AA5052/MWCNTs composites as a function of MWCNTs weight percentage $(0.05,0.1,0.2$, and 0.3$)$ produced by the stir casting technique. The wear rate of AA5052-MWCNTs composite materials decreases with increasing MWCNTs content. The wear rate decreases gradually from $8.3 \times 10^{-6} \mathrm{~g} / \mathrm{m}$ (base Matrix) to $7 \times 10^{-7} \mathrm{~g} / \mathrm{m}$ by increasing MWCNTs content up to $0.3 \mathrm{wt} . \%$.

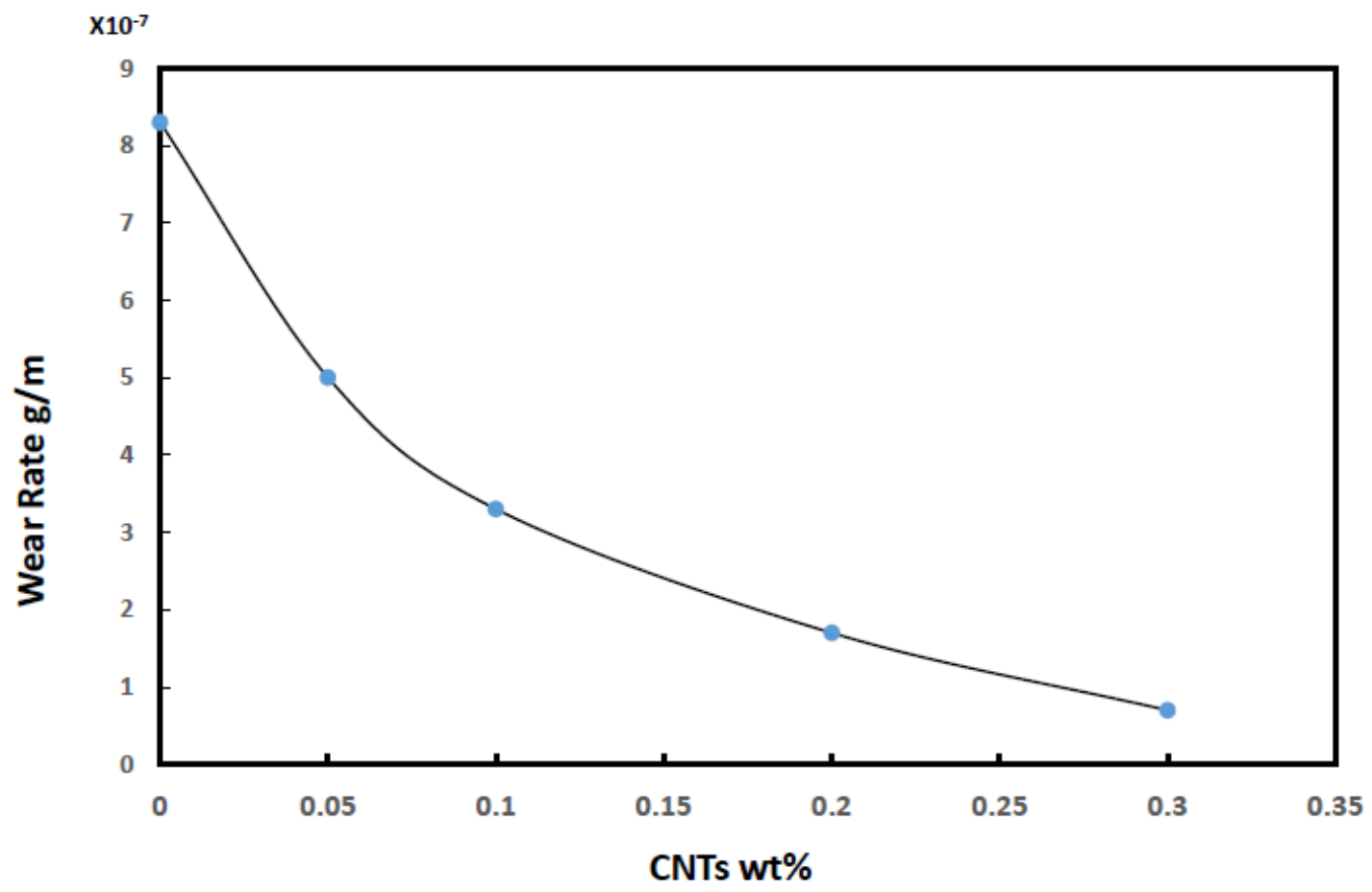

Fig.6: Wear rate obtained from room temperature abrasive wear testes for AA5052/MWCNTs composites as a function of MWCNTs \%

The dominant role played by the MWCNTs in enhancing the wear characteristics. MWCNTs were observed to be either partially or fully crushed, forming a carbon film that covered the surface and acted as a solid lubricant, enhancing the wear behavior significantly [33]. 


\subsection{Corrosion Test Results}

Figure 7 shows the anodic and cathodic polarization curves (Tafel plots) for unreinforced Al-Mg alloy and composite AlMg/MWCNTs containing different weight percent. The anodic dissolution rate of an unreinforced AlMg alloy and Al-Mg reinforced with MWCNTs increases as the corrosion potential becomes more oxidizing. From these curves, it can be seen that the shape of the curves is almost the same. This suggests that the MWCNTs do not significantly affect the Tafel curves characteristics.

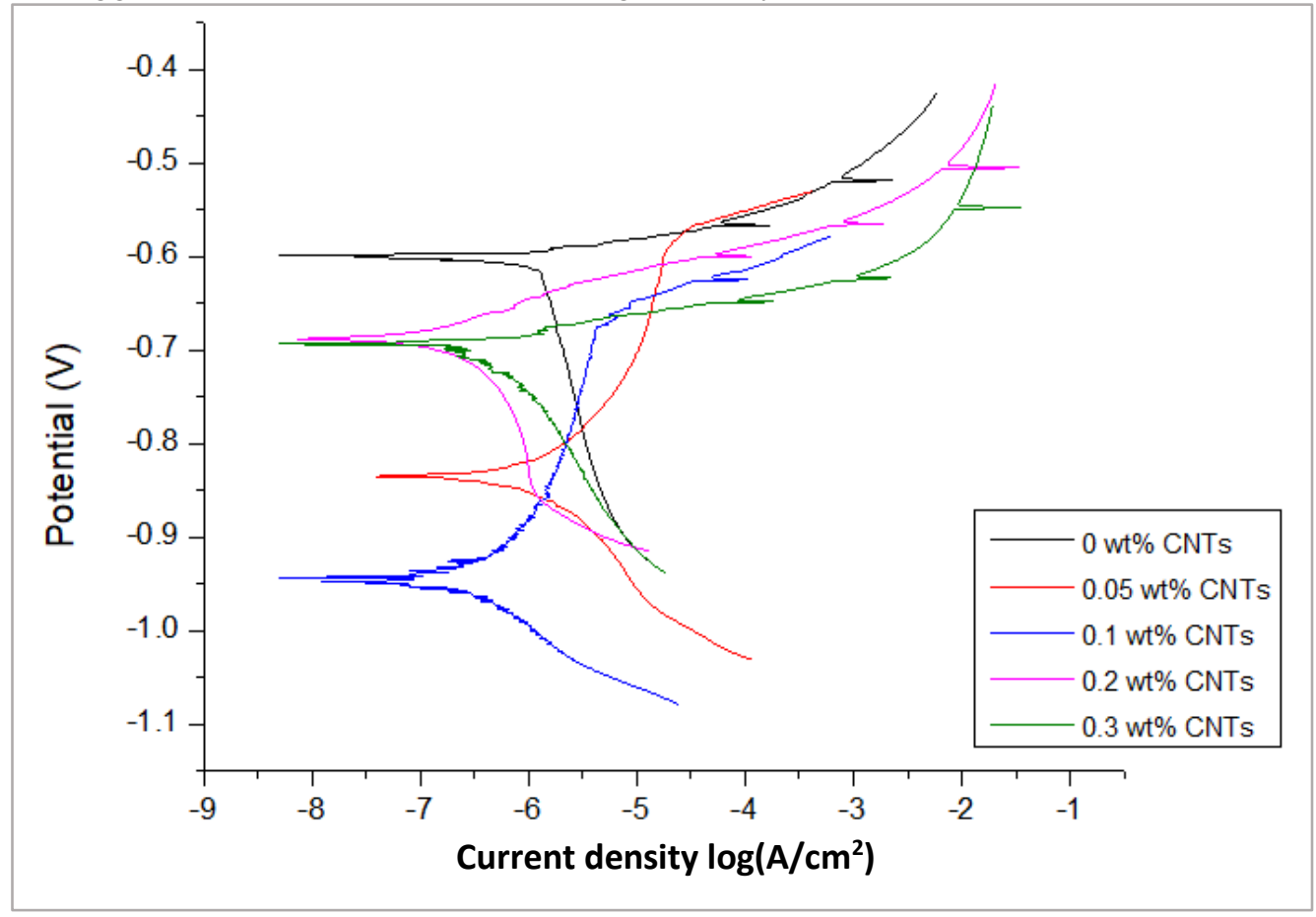

Fig.7: Potentiodynamic polarization curves for the Al-Mg-based composites containing different amounts of carbon nanotubes in $3.5 \% \mathrm{NaCl}$ solution

The corrosion current density was calculated by extrapolating the anodic and cathodic Tafel lines to the steady-state (corrosion) potential $\mathrm{E}_{\text {corr. }}$ Inspection of Table 3 shows that the corrosion potential $\left(\mathrm{E}_{\text {corr }}\right)$ slightly changes with an increase in MWCNTs content. In contrast, the corrosion current density ( $\mathrm{I}_{\text {corr. }}$ ) decreases. In addition, it was observed from the graph that the corrosion current decreased comparatively for all fabricated composites with base Al-Mg alloy.

The unreinforced alloy (AlMg) showed no better performance than the reinforced alloys, which contain $0.05,0.10$, and $0.2 \mathrm{Wt} \%$ MWCNTs. The anodic polarization curves show that with an increase in the amount of MWCNTs with $0.2 \mathrm{wt}$. \%, the corrosion potential $\left(\mathrm{E}_{\text {corr }}\right)$ shifts to a more noble potential, and the corrosion current density ( $\left.\mathrm{I}_{\text {corr }}\right)$ decreases. Beyond $0.2 \mathrm{wt}$ \% of MWCNTs, corrosion potential shifts to a positive direction, and the current density decreased.

The electrochemical parameters, including anodic and cathodic slopes ( $\beta \mathrm{a}$ and $\beta \mathrm{c}$ ) calculated from Tafel plots, and summarized in Table 3, it can be seen from Table 3 that the anodic and cathodic Tafel slopes ( $\beta \mathrm{a}$ and $\beta \mathrm{c}$ ) changed with increasing the amount of MWCNTs. This means that the addition of a reinforcing phase affects the anodic and cathodic reaction mechanisms. The passivation characteristics were not obvious, which indicates that the main corrosion form is pitting corrosion. In addition, $\beta \mathrm{a}$ and $\beta \mathrm{c}$ almost changed with increasing MWCNTs, indicating that the corrosion mechanism of the alloys is under mixed control. The corrosion rate is equally sensitive to any shifts in the anodic or oxidation reaction and the cathodic or reduction reaction. The corrosion process is mainly controlled by charge transfer and could be attributed to the oxide layer formed above the Al-Mg alloy. The effect of ohmic polarization on the corrosion current in an electrochemical corrosion cell is shown in Table 3. As the resistance of the solution increases with increasing the MWCNTs from 0.0 to $0.2 \mathrm{Wt} . \%$ in AlMg alloy, the magnitude of the potential drop of ohmic polarization in the cell increases, with a resulting 


\section{EFFECT OF MWCNTS ON MICROSTRUCTURE, DRY SLIDING WEAR, AND CORROSION BEHAVIOR OF AA5052/MWCNTS COMPOSITE}

decrease in the corrosion current of the cell from $1.3 \mu \mathrm{A} / \mathrm{cm}^{2}$ to $0.283 \mu \mathrm{A} / \mathrm{cm}^{2}$. Thus, an effective way to reduce the corrosion current in a corrosion cell is to increase the resistance to ionic current flow through the cell.

The cathodic and anodic reaction equations, respectively, shown below $\mathrm{O}_{2}+2 \mathrm{H}_{2} \mathrm{O}+4 \mathrm{e}^{-} \rightarrow 4 \mathrm{OH}^{-} \quad$ Cathodic reaction.
$\mathrm{Al} \rightarrow \mathrm{Al}^{3+}+3 \mathrm{e}^{-}$
Anodic reaction

With an increase in the concentration of $\mathrm{OH}^{-}$and $\mathrm{Al}^{3+}$, the reaction activation between $\mathrm{Al}^{3+}$ and $\mathrm{OH}^{-}$ increases sharply, forming flocculent insoluble hydroxide sediment [34].

$\mathrm{Al}^{3+}+3 \mathrm{OH}^{-} \rightarrow \mathrm{Al}(\mathrm{OH})_{3} \downarrow$

$\mathrm{Al}^{3+}+\mathrm{OH}^{-}+2 \mathrm{Cl}-\rightarrow \mathrm{Al}(\mathrm{OH}) \mathrm{Cl}^{-2}$

The corrosion rates $(\mu \mathrm{m} / \mathrm{year})$ for MMCs and their matrix alloys are summarized in Table 3 and illustrated in Fig. 8. The results revealed a decreasing trend of the corrosion rate values with increasing reinforcement content of MWCNTs in AlMg alloy, Fig. 8. The corrosion rate of composites decreases from 14.72 to $3.27 \mu \mathrm{m} / \mathrm{y}$ with increasing the MWCNTs content from 0.0 to $0.2 \mathrm{wt} \%$. The corrosion rate for the composite prepared with $0.2 \mathrm{Wt}$. \% MWCNTs are $78 \%$ lower than that of the unreinforced aluminum alloy.

Table 3: electrochemical parameters obtained from potentiodynamic polarization measurements for the corrosion of aluminum alloy with different amounts of MWCNTs in 3.5wt. \% NaCl solution

\begin{tabular}{|l|c|c|c|c|c|c|c|}
\hline \multicolumn{2}{|c|}{ CNT wt\% } & $\begin{array}{c}\mathrm{E}(\mathrm{i}=0) \\
\mathrm{mV}\end{array}$ & $\begin{array}{c}\mathrm{i} \text { corrosion } \\
\mu \mathrm{A} / \mathrm{cm}^{2}\end{array}$ & $\begin{array}{c}\mathrm{Rp} \\
\mathrm{kohm} . \mathrm{cm}^{2}\end{array}$ & $\begin{array}{c}\text { Beta a } \\
\mathrm{mV}\end{array}$ & $\begin{array}{c}\text { Beta c } \\
\mathrm{mV}\end{array}$ & $\begin{array}{c}\text { Corrosion } \\
\text { Rate } \\
\mu \mathrm{m} / \mathrm{Y}\end{array}$ \\
\hline Sample 0 & 0 & -605.4 & 1.3 & 11.27 & 28.8 & -470.8 & 14.72 \\
\hline Sample 1 & 0.05 & -837.6 & 1.17 & 16.58 & 120.1 & -111.5 & 13.26 \\
\hline Sample 2 & 0.1 & -948.1 & 0.289 & 63.55 & 118.6 & -92.3 & 3.27 \\
\hline Sample 3 & 0.2 & -690.4 & 0.289 & 81.07 & 38.5 & -199.6 & 3.27 \\
\hline Sample 4 & 0.3 & -700.8 & 0.6 & 57.71 & 23.4 & -182.3 & 6.91 \\
\hline
\end{tabular}

This trend suggests that the introduction of MWCNTs to the Al-Mg matrix improved the corrosion resistance of the matrix alloy. This improvement in the corrosion resistance of all MMCs may be due to a good connection of the matrix with the reinforcement. In addition, the $\mathrm{pH}$ value of $\mathrm{NaCl}$ solution is 7.5, and it is observed from the $\mathrm{pH}$-potential Pourbaix diagram of aluminum that aluminum passivates in the $\mathrm{pH}$ range of $4.0-8.0$ by the rapid formation of the aluminum oxide film $[35,36]$. Moreover, MWCNTs have poor conductivity and cannot act as the cathode of corrosion reaction. 


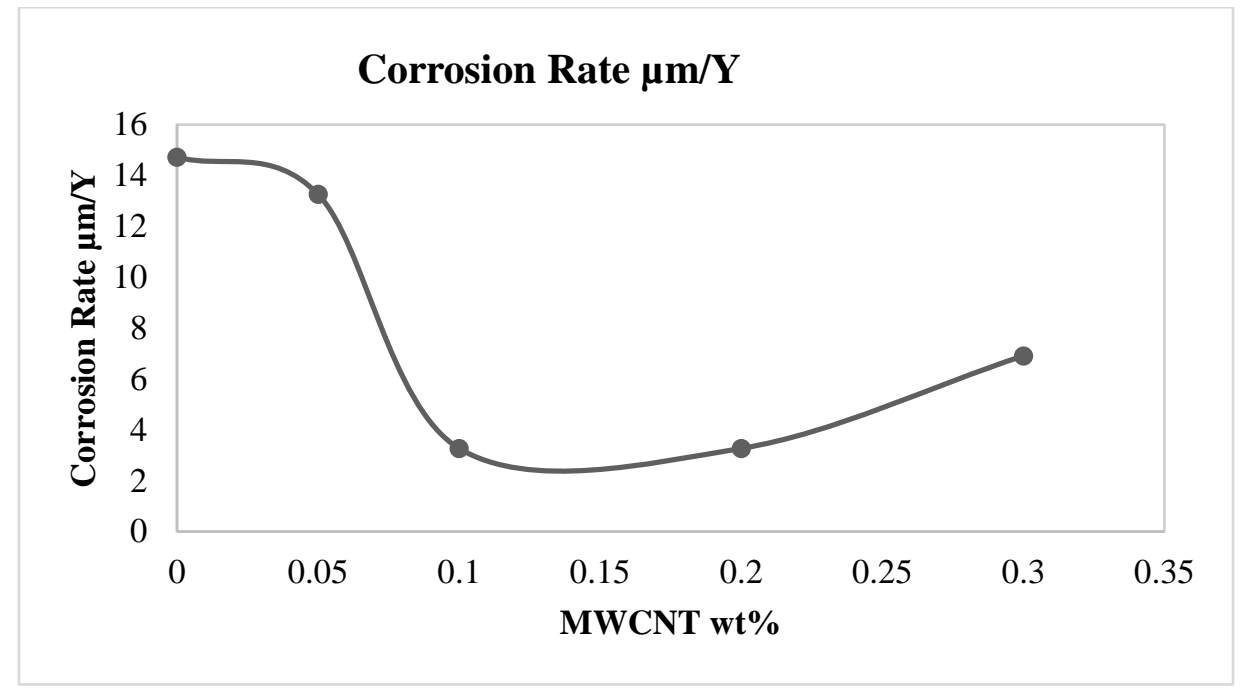

Fig. 8: Effect of reinforcement addition of carbon nanotubes (MWCNTs) on the corrosion rate of Al-Mg alloy in $3.5 \% \mathrm{NaCl}$ solution

It is observed from Fig. 8 that the amount of MWCNTs exceeds the critical value $(0.2 \mathrm{Wt} . \%)$, increasing the corrosion rate.

In addition, the corrosion rate of the Al-Mg alloy reinforced with 0.2 wt. \% MWCNTs exhibited a corrosion rate of $3.27 \mu \mathrm{m} / \mathrm{y}$ compared to $6.91 \mu \mathrm{m} / \mathrm{y}$ of the $\mathrm{Al}-\mathrm{Mg}$ reinforced with 0.3 wt. \% MWCNTs. This represents a 52\% reduction in corrosion rate. However, the corrosion rate of 0 and 0.3 wt. \% MWCNTs composite decreases from $14.72 \mu \mathrm{m} / \mathrm{y}$ to $6.91 \mu \mathrm{m} / \mathrm{y}$, respectively.

This behavior could be explained based on the processing conditions and the presence of MWCNTs that can affect the void content, dislocation density, and the precipitation of active phases in aluminum matrices [37]. In addition, the strain mismatch between the matrix and the reinforcement usually generates a higher density of dislocations in the matrix around the reinforcement.

\section{CONCLUSION}

The conclusions derived from this study can be summarized as follows:

1. The composites produced by the stir casting technique showed proper reinforcement distribution within the aluminum alloy matrix despite some microstructural defects such as porosity, particle clusters inherited in stir casting AA5052-MWCNTs composite materials.

2. The results revealed that the increase of CNT content from zero to $0.3 \mathrm{wt}$. \% causes a reduction in the average grain size value up to 6 times finer than the base material grain size.

3. The wear rate decreases gradually from $8.3 \times 10-6 \mathrm{~g} / \mathrm{m}$ (base Matrix) to $7 \times 10^{-7} \mathrm{~g} / \mathrm{m}$ by increasing MWCNTs content up to $0.3 \mathrm{wt} . \%$.

4. The corrosion rate of composites decreases from 14.72 to $3.27 \mu \mathrm{m} / \mathrm{y}$ with increasing the MWCNTs content from 0.0 to $0.2 \mathrm{wt} \%$.

5. The corrosion rate for the composite prepared with $0.2 \mathrm{Wt}$ \% MWCNTs are $78 \%$ lower than that of the unreinforced aluminum alloy.

\section{REFERENCES}

[1] B. Baradarani and R. Raiszadeh, Precipitation hardening of cast Zr-containing A356 aluminium alloy, Mater. Des. 32 (2) (2011) 935-940.

[2] Jong Gil Park, Dong Hoon Keum, Young Hee Lee a, Strengthening mechanisms in carbon nanotube-reinforced aluminum composites, Carbon 95 (2015) 690-698. 
[3] R. Pérez-Bustamante, F. Pérez-Bustamante, I. Estrada-Guel, L. Licea-Jiménez,M. MikiYoshid, R. Martínez-Sánchez, Effect of milling time and CNT concentration on hardness of CNT/A12024 composites produced by mechanical alloying, Materials Characterization 75 (2013) 13-19.

[4] T.H. Nam, G. Requena, P. Degischer, Thermal expansion behaviour of aluminum matrix composites with densely packed SiC particles, Compos. A: Appl. Sci. Manuf. 39 (5) (2008) 856-865.

[5] M. Jahedi, B. Mani, S. Shakoorian, E. Pourkhorshid, M. Hossein Paydar, Deformationrate effect on the microstructure and mechanical properties of Al-SiCp composites consolidated by hot extrusion, Mater. Sci. Eng. A 556 (2012) 23-30.

[6] M. Jahedi, M.H. Paydar, M. Knezevic, Enhanced microstructural homogeneity in metalmatrix composites developed under high-pressure double-torsion, Mater. Charact. 104 (2015) 92-100.

[7] M. Zabihi, M.R. Toroghinejad, A. Shafyei, Evaluating the mechanical behavior of hot rolled Al/alumina composite strips using shear punch test, Mater. Sci. Eng. A 618 (2014) 490-495.

[8] W. Hoziefa, S. Toschi, M.M.Z. Ahmed, Al. Morri, A.A.Mahdy, M.M. El-Sayed Seleman, I. El-Mahallawi , L. Ceschini, and A. Atlam, Influence of friction stir processing on the microstructure and mechanical properties of a compocast AA2024-Al2O3 nanocomposite, Materials and Design 106 (2016) 273-284.

[9] Y. Yao, L. Chen, Processing of B4C particulate-reinforced magnesium matrix composites by metal-assisted melt infiltration technique, J. Mater. Sci. Technol. 30 (7) (2014) 661-665.

[10] Ansari R, Rouhi H, Sahmani S., Calibration of the analytical non local shell model for vibrations of double walled carbon nanotubes with arbitrary boundary conditions using molecular dynamics. Int J Mech Sci 53 (2011) 786-92.

[11] Brischetto S,Carrera E. Classical and refined shell models for the analysis of nanoreinforcedstructures. Int J Mech Sci 55 (2012) 104-117.

[12] Deepak BP, Ganguli R, Gopalakrishnan S. Dynamics of rotating composite beams: acomparative study between CNT reinforced polymer composite beams and laminated composite beams using spectral finite elements. Int J Mech Sci 64 (2012) 110-126.

[13] Kiani K.Vibration analysis of elastically restrained double-walled carbon nanotubes on elastic foundation subjected to axial load using non local shear deformable beam theories. Int J Mech Sci 68 (2013) 16-34.

[14] Li C. A nonlocal analytical approach for torsion of cylindrical nano structures and the existence of higher-order stress and geometric boundaries. Compos Struct 118 (2014) 607621.

[15] Li C, Yao L, Chen W, Li S. Comments on non local effects in nano cantilever beams. Int J Eng Sci 87(2015) 47-57.

[16] Li C. Torsional vibration of carbon nanotubes: comparison of two non local models and a semi-continuum model. Int J Mech Sci 82(2014) 25-31.

[17] Tjong SC. Recent progress in the development and properties of novel metal matrix nanocomposites reinforced with carbon nano tubes and graphene nano sheets. Mater Sci Eng R 74(2013)281-350.

[18] Fogagnolo JB, Velasco F, Robert MH, Torralba JM. Effect of mechanical alloying on the morphology, microstructure and properties of aluminium matrix composite powders. Mater Sci Eng A 342 (2003) 131-143.

[19] Suryanarayana C. Mechanical alloying and milling. Prog Mater Sci 46 (2001)1-184.

[20] Esawi A, Morsi K. Dispersion of carbon nanotubes (CNTs) in aluminum powder. Compos A 38 (2007) 646-650.

[21] Mohd Rizwan Jafar, D.S. Nagesh, Effect of process control agent and mechanical milling on the embedment and uniform dispersion of CNTs and B4C in aluminium matrix, Materials Today: Proceedings (2021) in press.

[22] M Sanjua, M Saravanana, G Gokul Krishna, S Senthil Kumaran, An Investigation of Wear 
Behavior on AA7075 MMC reinforced with CNT and Fly ash Composites, Materials Today: Proceedings 22 (2020) 2460 -2468.

[23] B. Madhusudhana Reddy, Anand P, Exploration of properties of Al 5056/CNT metal matrix nano composites, Materials Today: Proceedings 18 (2019) 4360-4365.

[24] Seyed Kiomars Moheimani, Mehran Dadkhah, Mohammad Hossein Mosallanejad and Abdollah Saboori, Fabrication and Characterization of the Modified EV31-Based Metal Matrix Nanocomposites, Metals (2021), 11, 125.

[25] A. Magdy, Amir A. Mahdy, E.S. Mosa and A. Kandil, MWCNTs Reinforced Aluminum Alloy (AA5052) Fabricated by Stir Casting Process, Al-Azhar Engineering Fifteenth International Conference, March 13 -15, (2021) 670-676.

[26] Hassan Zare ,Mohammad Jahedi ,Mohammad Reza Toroghinejad ,Mahmoud Meratian , MarkoKnezevi, Compressive, shear, and fracture behavior of CNT reinforced Al matrix composites manufactured by severe plastic deformation, Materials and Design 106 (2016) 112-119.

[27] P. Quang, Y.G. Jeong, S.C. Yoon, S.H. Hong, H.S. Kim, Consolidation of 1 vol.\% carbon nanotube reinforced metal matrix nanocomposites via equal channel angular pressing, Journal of Materials Processing Technology 187-188 (2007) 318-320.

[28] D.K. Lim, T. Shibayanagi, A.P. Gerlich, Synthesis of multi-walled CNT reinforced aluminium alloy composite via friction stir processing, Materials Science and Engineering A 507 (2009) 194-199.

[29] G.V.N.B. Prabhakar, Y.V.R.S.N. Pavan Kumar, P. Dileep Kumar,

B. Prasanna Kumar, M. Gopi Raju, Sk. Naseema, N. Ravi Kumar, M. Jagannatham, B. Ratna Sunil, Producing Al5083-CNT composites by friction stir processing: influence of grain refinement and CNT on mechanical and corrosion properties, Materials Today: Proceedings 15 (2019) 44-49.

[30] Abhishek Sharma, Hidetoshi Fujii , Jinu Paul, Influence of reinforcement incorporation approach on mechanical and tribological properties of AA6061- CNT nanocomposite fabricated via FSP, Journal of Manufacturing Processes 59 (2020) 604-620.

[31] T. R. Mc Nelley and P. N. Kalu, Microstructural refinement by thermo mechanical treatment of a cast and extruded $6061 \mathrm{~A} / \mathrm{Al} 2 \mathrm{O} 3$ composite, Scripta Metallurgica et Materialia, 25 (1991) 853-858

[32] S. Sattari, M. Jahani, and A. Atrian, Effect of volume fraction of reinforcement and milling time on physical and mechanical properties of A17075-SiC composites fabricated by powder metallurgy method, Powder Metallurgy and Metal Ceramics, 56 (2017) 283-292.

[33] U. Abdullahi, M. A. Maleque, and U. Nirmal, Wear mechanisms map of CNT-Al nanocomposite, Procedia Eng 68 (2013) 736-742.

[34] M. A. Amin, A newly synthesized glycine derivative to control uniform and pitting corrosion processes of Al induced by SCN À anions - Chemical, electrochemical and morphological studies, Corros. Sci., 52 (2010) 3243-3257.

[35] A. Włodarczyk and M. Adamiak, Structure, properties and corrosion resistance of PM composite materials based on EN AW-2124 aluminum alloy reinforced with the Al2O3 ceramic particles, 163 (2005) 27-32.

[36] S. Das, Y. L. Saraswathi, and D. P. Mondal, Erosive - corrosive wear of aluminum alloy composites : Influence of slurry composition and speed, 261 (2006) 180-190.

[37] D. Stephen, S. Cramer, and B. Covino Jr, American Society of Metals, Metals Handbook, vol. 13B - Corrosion Materials. ASM International, Materials Park, 2005. 